\title{
A Defence of Voluntary Sterilisation
}

\author{
Paddy McQueen ${ }^{1}$ (D)
}

Published online: 10 September 2019

(c) The Author(s) 2019

\begin{abstract}
Many women identify sterilisation as their preferred form of contraception. However, their requests to be sterilised are frequently denied by doctors. Given a commitment to ensuring women's reproductive autonomy, can these denials be justified? To answer this question, I assess the most commonly reported reasons for a denied sterilisation request: that the woman is too young, that she is child-free, that she will later regret her decision, and that it will lower her well-being. I argue that these worries are misplaced and hence insufficient reasons for denying a request. I also argue that even if concern for patient welfare provides doctors with a valid reason to withhold sterilisation, this is overriden by respect for patient autonomy and the importance of enabling women's reproductive control. Consequently, I suggest that adequately informed, decision-competent women should have their requests for sterilisation agreed to, even if they are young and/or child-free. In addition, I examine the impact of pronatalism on how women's requests are understood and responded to by doctors. I show that the equation of women with motherhood can make it unjustifiably hard for them to access sterilisation, especially if they are child-free. Consequently, part of ensuring women's access to sterilisation involves challenging pronatalist beliefs and practices.
\end{abstract}

Keywords Autonomy $\cdot$ Contraception $\cdot$ Medical ethics $\cdot$ Pronatalism $\cdot$ Regret Reproductive control $\cdot$ Sterilisation

\section{Introduction}

In 2015, Holly Brockwell wrote an article in the Guardian newspaper about her struggle to be sterilised (Brockwell 2015). She was first denied sterilisation at the age of 26 and had three subsequent requests denied in the following three years, despite sterilisation being freely available on the UK's National Health Service. Brockwell maintained that her request was based upon a strong, stable conviction

Paddy McQueen

paddy.mcqueen@swansea.ac.uk

1 Swansea University, JC029 James Callaghan Building, Singleton Park SA2 8PP, UK 
that she never wanted to have children. However, her doctors told her that she was too young and that she would later regret her decision. Brockwell's case is not unusual. Women have long complained about being unable to access sterilisation (Campbell 1999; Borrero et al. 2008; Kluchin 2009, pp. 123-124). Indeed, Richie (2013, p. 38) reports that such accounts are 'ubiquitous'. Given the importance of ensuring women's reproductive freedom-which includes control over if, and when, to have children, as well as adequate access to effective contraception-it is important to examine whether doctors can be justified in withholding access to sterilisation. To do so, I assess the most commonly reported reasons for a denied sterilisation request: that the woman is too young, that she is child-free, that she will later regret her decision, and that it will lower her well-being. I show that these worries are misplaced and do not justify withholding access to sterilisation. I also argue that even if concern for patient welfare does give doctors a valid reason to deny a sterilisation request, this can be overridden by respect for patient autonomy. Consequently, I conclude that decision-competent, adequately informed women should have their requests for sterilisation agreed to.

In addition, I examine and defend the reasons women have for requesting sterilisation in the first place. The choice of what form of contraception to use is a significant and often difficult one to make. Thus, it is important to consider why some women prefer sterilisation to alternative methods. This will help individuals who are deliberating about what form of contraception could be best for them and alleviate clinicians' concerns about sterilisation. Finally, I examine how attitudes towards, and requests for, sterilisation are affected by women's identity. This is an important issue to address because doctors currently control access to sterilisation and thus it matters greatly how they decide whom sterilisation is appropriate and inappropriate for. Of especial relevance is the pervasiveness of pronatalism, which equates women with motherhood and asserts that parenting is essential to their happiness and fulfillment. This can make it excessively difficult for women to be sterilised, particularly if they are child-free. Thus, in addition to defending women's access to sterilisation, I highlight some important dynamics that impact upon women's reproductive autonomy within the practical, non-ideal context of medical decision-making.

\section{What is Sterilisation?}

Sterilisation is a form of permanent contraception. There are several different forms of female sterilisation: tubal occlusion, in which the Fallopian tubes are closed with clips or rings; hysteroscopic sterilisation, in which implants are used to block the Fallopian tubes; and salpingectomy, in which the Fallopian tubes are removed. Sterilisation is very effective: on average, one woman in 200 who is sterilised will become pregnant during her lifetime. Although it is typically classified as irreversible, it is possible to reverse certain forms of sterilisation. The success rate (i.e. pregnancies carried to term) varies depending upon the method of sterilisation, ranging from 20 to $70 \%$ (Zite and Borrero 2011, p. 338). Given that the 
probability of success is often below $40 \%$, it is generally treated as if it is irreversible and those requesting it are advised to consider it as such (National Health Service 2015). ${ }^{1}$

\section{Deciding to Request Sterilisation}

Most women request sterilisation because (a) they do not want to have any (more) children; and/or (b) their health will be at risk if they become pregnant. There are many reasons why a woman may not want to have any (more) children, including: satisfaction with her current family size; the economic costs of having a/another child; the impact of parenting on her career; the environmental impact of raising children; the belief they are too old to have a/another child; greater opportunity for self-fulfilment; marital contentment; uninterest in parenthood (Veevers 1980; Morrell 1994; Campbell 1999; Gillespie 2003; Park 2005; Kelly 2009). However, even if one does not want to have any (more) children, why choose sterilisation over other forms of contraception? What might be appealing/preferable about it?

Sterilisation is a quick, relatively simple procedure that is not dangerous to most women's health, is $99 \%$ effective at preventing pregnancy and has very few negative side effects. Unlike the pill, sterilisation does not interfere with women's hormone levels or cause weight gain, alterations in mood, breast tenderness, or decreased libido. Long-term use of the pill has also been linked with depression and an increased risk of serious health conditions, such as thrombosis and breast cancer. Furthermore, sterilisation allows for more spontaneous and, for some, more intimate and physically pleasurable sex than condoms (Higgins and Hirsch 2008). These points can explain why some women prefer sterilisation over condoms and the pill (Campbell 1999). However, there are also several disadvantages of sterilisation (National Health Service 2015). In the very unlikely event that it fails and the woman becomes pregnant, then there is an increased risk that it will be an ectopic pregnancy. With tubal occlusion, there is a very small risk of complications such as internal bleeding or damage to other organs. As a surgical procedure, sterilisation is more invasive than other forms of contraception and carries the risk of infection. Finally, it does not protect a person from STIs. Some women may be put off by these drawbacks, whilst others are untroubled by them, especially in comparison to condoms and the pill.

Sterilisation is also permanent and difficult to reverse. For women who think they might want to have a/another child, this is clearly a strong reason against it. However, for other women, it is the main attraction of sterilisation. Consider someone whose life will be at severe risk were she to become pregnant or who would pass on a fatal, painful genetic disease to her offspring. She should not become pregnant and hence the effectiveness and permanence of sterilisation provide her with good reason to choose it. The same reasoning applies, for example, to a woman in her late 40s who has four children and is certain she does not want any more. However,

\footnotetext{
1 In the UK, the National Health Service states that it rarely offers reversal procedures, which means that one will have to obtain the operation privately and hence at significant financial cost.
} 
younger women with fewer or no children also request sterilisation. Given the possibility that they may change their minds and later want to have (more) children, it could be argued that they should not opt for a form of contraception that is permanent and hard to reverse when non-permanent and easily reversed options are available. Specifically, long-lasting IUDs seem to offer the benefits of sterilisation without the potential costs that arise if one later changes one's mind about having (more) children. Should younger women with no children, or one or two children, necessarily choose IUDs instead? ${ }^{2}$

Consider a woman in her late 20s who has a strong, persistent desire for a childfree life. She sees her friends becoming parents and feels ever more certain that motherhood is not for her. She accepts that it is possible she might change her mind and want to have children of her own. However, based on her feelings, values and experiences to date, she does not think this will happen. Furthermore, she is familiar with research findings - which I outline below - that indicate low levels of poststerilisation regret and similar levels of well-being between parents and voluntarily child-free individuals. Finally, she accepts the risk that she may later regret her decision but believes that she will be able to cope well with such a scenario. She might seek to adopt or become a foster parent, or else focus on enjoying the benefits of being child-free (perhaps she has a tendency to make the best of her current situation, rather than dwelling on what might have been). Certain that she wants to live a child-free life, and confident she will not change her mind about this, she decides that sterilisation is the best method of contraception for her.

This woman does not seem irrational or imprudent in preferring sterilisation over an IUD. The permanency of sterilisation may be a sufficient reason for some, perhaps most, women to choose an IUD instead. It also gives all women reason to deliberate carefully and extensively about whether it is right for them. Finally, it means that women who are unsure whether they will want (more) children have a good reason not to request it. However, it does not mean that all women should necessarily prefer other forms of contraception over sterilisation and are unreasonable if they do not do so. People often make decisions that have permanent, irreversible consequences and which they may later regret (e.g. getting a tattoo; marrying; undergoing plastic surgery; having children; donating a kidney). This does not mean they should - and are irrational if they do not - therefore choose the less permanent and/or more easily reversed option. Indeed, for determinedly child-free women, or women who are happy with their current family size, the permanence of sterilisation is the major reason why they request it (Campbell 1999; Borrero et al. 2008).

Sterilisation can provide these women with a sense of control, satisfaction, independence, relief and/or finality, allowing them to commit fully to their preferred lifestyle and freeing them from worries of pregnancy (Borrero et al. 2008). To quote one voluntarily sterilised woman, 'Having had your tubes tied does allow you to

\footnotetext{
2 Some women, such as Holly Brockwell, are unable to use IUDs owing to a copper allergy. In Brockwell's case, her doctors still refused to agree to her request for sterilisation, thus requiring that she use the pill, condoms, refrain from having reproductive sex or that her partner be sterilised instead (an option suggested by one of her doctors).
} 
kind of proceed with the rest of your life' (Borrero et al. 2008, p. 315). Sterilised women may be better able to plan for the long-term future, knowing that they will not have to think about having (more) children. ${ }^{3}$ It is not always/necessarily preferable or more rational to keep all our options open, especially if this prevents us from fully embracing any one of them. As Dworkin (1982) has argued, less choice can sometimes be better than more. Perhaps we will be able to focus better on the life we want to live if we foreclose certain alternatives. If a woman is confident that she does not want (more) children, but still harbours occasional, unwanted doubts about this, then choosing to be sterilised may offer a welcome resolution in which such doubts are quashed. Furthermore, a woman who is determined to live a child-free life, or to limit her family size, for environmental reasons - such as the environmental impact of raising children and/or concerns about overpopulation-could want a permanent, irreversible form of contraception to ensure she realises these core ethical/political values. Perhaps, owing to societal and familial pressure, she worries that she will later be tempted to have a/another child, despite believing and desiring strongly that she should not. Sterilisation frees her from such worries and binds her to what she sees as the right way to live. Consequently, there can be advantages to choosing a contraceptive method that is permanent and difficult to reverse, even for young and/or child-free women.

A final relevant consideration is whether a woman's age should affect her choice of contraception. It might be argued that younger women, perhaps those under 30, should not request sterilisation because they lack the self-knowledge and life-experience necessary to be certain that they do not/will not want to have (more) children. In response, it can be observed that these women, such as Holly Brockwell, are intelligent, self-reflective individuals who can give clear and persuasive arguments in defence of their preference for sterilisation. Their relative lack of life-experience does not mean that they are incapable of making significant life-choices based on strong and persistent desires and values; there is no reason to assume they are less able to act autonomously than older women. Women in their 20 s often make the permanent, life-changing decision to have children and this choice is not seen to be problematic simply in virtue of their age. Typically, we do not say they should necessarily wait until they are older, in case they change their mind, and it would certainly be wrong to prevent them from having a child on this basis. ${ }^{4}$ Furthermore, it is not necessarily the case that one becomes a more capable decision-maker as one ages. As Benn and Lupton (2005, p. 1324) note, 'it is possible to become more foolish as life progresses, rather than wiser'. Thus, a young woman's age does not mean she should necessarily opt against sterilisation. Some women, even those who are young and/or child-free, can have good reason to prefer sterilisation to other forms of contraception.

\footnotetext{
${ }^{3}$ If she is single and wants to be in a long-term relationship, then it may help her to achieve this. This is because her partner will know that their relationship will not involve having children of their own (or, at least, is unlikely to, given the rates of successful reversal). They can commit to one another in the light of this knowledge.

4 Admittedly, women's child-bearing choices are not all treated in the same way. Reactions to them are shaped by the woman's race, socio-economic status, sexuality, etc. However, the substantive point is that the woman's age is not a good reason to prevent her from having a child, providing she is a legal adult.
} 


\section{Can Denied Sterilisation Requests be Justified?}

As noted in the Introduction, many women report having their requests denied, despite clinicians generally being willing to provide alternative contraceptive methods. Given the foregoing defence of a woman's preference for sterilisation, coupled with the importance of respecting their bodily and reproductive autonomy, can these denials be justified ${ }^{5}$

Withholding sterilisation is appropriate if the patient is not a legal adult or if she is being coerced into requesting it. It can also be appropriate if the patient is not competent to make a decision about sterilisation. Defining and identifying competence is a complex issue (Beauchamp and Childress 2013, pp. 114ff.). Following Buchanan and Brock (1989, pp. 23-25), competence can be understood as comprising several capacities, which include understanding, communication, reasoning and deliberation, as well as a set of values/conception of the good. It is also best characterised as a 'process' rather than an 'outcome' (Buchanan and Brock 1989, p. 47ff.). Competence is primarily a matter of how a decision is made, rather than solely concerning the content/outcome of that decision. This means that when doctors assess a patient's request for sterilisation, they should focus on whether she has exercised the requisite competence capacities in making her decision; that she understands what sterilisation involves, including its advantages and disadvantages/risks; that she has reflected on whether sterilisation is consistent with her longer-term values and preferences, including the relative strength and stability of these values; and that she has discussed the treatment and alternative options with suitable clinicians. ${ }^{6}$

An important implication of this 'process' view is that doctors should not assess a patient's competence to make a decision about sterilisation solely based on what they think about the (un)reasonableness of it. In particular, doctors should not conclude that the patient lacks competence if they think sterilisation is a bad/unreasonable choice to make. As Ganzini et al. (2004, p. 264) argue, 'clinicians should not conclude that patients lack decision-making capacity just because they make a decision contrary to medical advice'. For example, the fact that a doctor thinks sterilisation is 'too risky', given its permanence and the possibility of regret, does not mean that the patient's request for it indicates noncompetence (e.g. because, according to the doctor's judgement, the patient is irrationally risk-averse). Consequently, clinicians ought not to deny a sterilisation request on the grounds of non-competence simply because they do not think a person should want to be sterilised. A similar logic applies to a patient who

\footnotetext{
5 Some people will argue that all contraception is morally unacceptable and hence should never be offered to women. I cannot engage directly with this position here and instead assume that there is nothing inherently immoral in using birth control.

${ }^{6}$ Competence is also decision-relative, meaning that the requirements for being competent to make a decision vary according to the nature of the decision in question. For example, level of self-reflection necessary to be competent to decide whether to use the pill is lower than that required for deciding to be sterilised, given the latter's permanence.
} 
requests euthanasia: a doctor may think this is the wrong choice for them to make, but they should not take this as conclusive evidence that the patient lacks decision-making competence.

Nevertheless, there are some clear-cut cases where the patient is not competent to request sterilisation and this is good grounds for doctors withholding it from them. The first concerns a patient who lacks an adequate understanding of the procedure. For example, she may believe that sterilisation is non-permanent or easily reversed. The second concerns a patient whose preferences or life-plans are clearly inconsistent with the nature of the treatment. This would occur if a woman requested sterilisation but also expressed a desire to have children of her own in the future. Finally, a woman may not be able to deliberate and reason adequately about sterilisation. This can be because of a permanent psychological impairment or disability, such as a severe learning disability. Alternatively, a woman can be temporarily noncompetent, which might occur if she is suffering from severe post-natal depression. Her depression may mean she cannot adequately reflect and act on her core values and preferences, which would guide her choice were she not depressed. In all these cases, clinicians can be justified in withholding sterilisation. ${ }^{7}$

However, can there be good reasons to deny sterilisation requests from decisioncompetent women who understand the nature and implications of sterilisation and have a strong, abiding preference not to have any (more) children? A possible pragmatic reason is cost: if sterilisation is significantly more expensive than other forms of contraception, then doctors may need to withhold it when cheaper, alternative forms of contraception are available. This only applies in a public healthcare context, where budgets are extremely stretched and treatment is provided at no, or a much-reduced, cost to the patient. It will not apply if the patient is privately funded. The cost of sterilisation varies depending on the procedure and the country, but is around $\$ 3000 / £ 2000$ (Trussell et al. 2009). Although more expensive than alternative contraceptive methods, this will not necessarily be the case over the course of a lifetime. Regular use of the pill or IUDs over many years is likely to be more expensive, because sterilisation is a one-off treatment (Zite and Borrero 2011, p. 339). Admittedly, this depends on the age of the woman. If she has only a few years of fertility left, then a single IUD will be required. This would likely make sterilisation the more expensive option. However, for younger women who do not want any (more) children, sterilisation could well be a more cost-effective option. ${ }^{8}$

An ethical reason for witholding sterilisation can be derived from the Hippocratic tradition's commitment 'to do no harm'. Some doctors may feel uneasy about performing surgery on a patient that damages/stops the functioning of a healthy body part, considering this an unnecessary or otherwise unwarranted harm. Several points can be made in response to this concern. First, it is not clear that voluntary sterilisation does constitute a harm to the patient. Preventing the body from reproducing

\footnotetext{
7 At least temporarily: if the patient develops sufficient knowledge of the procedure or reasoning ability, then a denied request may no longer be warranted.

${ }^{8}$ Sterilisation is also considerably cheaper than many treatments offered to patients, such as IVF, and its cost needs to be weighed against the emotional and financial impact of unwanted pregnancy.
} 
does not in itself present a risk to the patient's physical health, provided that the procedure is performed by qualified physicians using safe, suitable equipment. As outlined above, there are risks attached to being sterilised. However, (a) these complications are rare; and (b) there are risks to many surgical treatments, which are nevertheless offered to patients who decide whether or not to undergo them. In addition, the notion of 'harm' can be construed as the 'thwarting, defeating, or setting back of some party's interests' (Beauchamp and Childress 2013, p. 153). If a woman desires strongly to be sterilised-and sees it as in accord with her life-plans, values, etc. - then it is hard to see how it constitutes a harm to her. ${ }^{9}$ This is especially true of women for whom unwanted pregnancy would be extremely distressing and hence psychologically harmful (given the dangers of pregnancy and its impact upon the body, it may also be considered physically harmful). Sterilisation can be seen to prevent harm to these women.

Furthermore, even if voluntary sterilisation is considered to inflict a physical 'harm' on a woman, in the sense of destroying a natural faculty/function of the body, many people believe that clinicians can and should perform such procedures. Most notably, defenders of voluntary euthanasia hold that it can be permissible for doctors to actively bring about the death of a patient. The justification for this is that the doctors' actions will be for the good of the patient, in the sense of enabling her autonomy and/or promoting her well-being. This may be taken to show that treatment which a patient requests autonomously does not constitute a medical harm (or medically relevant harm) to her, even if it is physically damaging. It also indicates that healthcare ethics need not, and should not, be reduced to the avoidance of doing harm to the patient. It also includes the principles of beneficence and respect for autonomy. ${ }^{10}$ As Beauchamp and Childress (2013, p. 202) observe, 'Attending to the welfare of patients - not merely avoiding harm-embodies medicine's goal, rationale and justification'. Importantly, promoting patient welfare need not be reduced to the restoration of 'normal' (e.g. pre-illness or pre-injury) functioning. Especially given technological advances in medicine, there are many ways in which patients' welfare can be improved by doctors, beyond rectifying illness or injury. Benn and Lupton (2005, p. 1323) note that much surgery performed today is life-enhancing rather than life-preserving. Clinicians also regularly provide non-surgical interventions aimed at enhancing a patient's quality of life, such as administering IUDs and offering therapeutic services such as counselling. The same applies to the abortion of a pregnancy that does not pose a serious threat to the woman's life. As I discuss

\footnotetext{
9 Clearly, non-voluntary sterilisation does constitute a harm to the patient, both in thwarting her interest in having children (assuming she has one) and in violating her autonomy.

${ }^{10}$ Whereas the principle of non-maleficence relates to a negative obligation not to harm the patient, the principle of beneficence incorporates the positive obligation to promote the patient's welfare and autonomy. As I argue below, the importance of ensuring that women enjoy reproductive control, coupled with women's dependence on doctors for access to IUDs and sterilisation, generates a positive obligation for doctors to provide these methods of contraception to decision-competent adult patients. A patient's right to reproductive autonomy places not only a negative obligation on doctors to refrain from making her pregnant, but also a positive obligation to assist her in avoiding pregnancy. The most obvious and appropriate way this can be done is through the provision of effective contraception.
} 
below, many sterilised women report that it has had a very positive effect on their well-being (Campbell 1999; Borrero et al. 2008). This also challenges the idea that voluntary sterilisation constitutes a 'harm'.

In response, it might be objected that healthcare should focus on satisfying medical needs and interests-perhaps those which are classified as vital or basic - and that sterilisation does not relate to such a need or interest. This will apply particularly to public (i.e. state-funded) healthcare, where budgetary constraints mean that clinicians must be selective in which treatments to offer. However, it might also apply to private healthcare, if one thinks that it too should be restricted to medically necessary treatment. Setting aside the issue of specifying what 'vital' or 'basic' needs and interests are, and how to determine what is 'medically necessary' treatment, it seems reasonable to hold that reproductive control is a sufficiently important and medically relevant interest for it to be a part of healthcare. It is essential to women's bodily autonomy, physical health and psychological well-being that they control if or when they become pregnant (not least, because of the negative consequences of unwanted pregnancies). This is why many/most people do not object to state-funded institutions such as the UK's National Health Service providing the pill or IUDs to patients free of charge. Even if healthcare is restricted to meeting basic, vital or clinical needs, then this should include the provision of the patients' preferred form of contraception.

Perhaps, though, there is only a requirement for healthcare to offer some methods of contraception. If so, then a justification is needed as to why IUDs and the pill should be provided, but not sterililsation. I have already ruled out the cost of sterilisation as providing this justification. An alternative reason, which is frequently offered by doctors, is that sterilisation is permanent (Campbell 1999). This concern is not limited to clinicians: whilst defending women's reproductive freedom, Jackson (2001, p. 19) suggests that 'sterilisation's defect is its permanence'. Thus, clinicians may feel justified in denying a sterilisation request when they can administer alternative non-permanent contraceptive methods. However, the permanency of sterilisation is not a convincing justification for doctors to deny a request for it. That a medical treatment is permanent (and irreversible) is not itself a reason to withhold it. To the contrary, doctors often perform such treatments or facilitate women with making choices that have permanent effects, such as providing IVF. Whilst its permanence can be a good reason for a woman to decide against sterilisation, it is not a strong reason for doctors to withhold it.

A second very common reason for denied sterilisation requests is that the woman is too young. This generally means 'under 30', but women in their early or mid-30s are also denied sterilisation on this basis (Campbell 1999; Richie 2013; Brockwell 2015). In a survey of doctors, Lawrence et al. (2011, p. 108) found that $70 \%$ of participants were 'somewhat or very likely' to discourage a 26-year-old mother-of-one from being sterilised after her second birth when her husband disagreed with this decision. ${ }^{11}$ A 34-year-old woman said, 'I asked again and they were like you're too young. She [the doctor] just said, if you want it, you got to go to another doctor.

11 If the husband agreed with the decision, then the figure dropped to $42 \%$. 
It was just point blank... They will not tie my tube' (Borrero et al. 2008, p. 316). However, appealing to the patient's age is not a persuasive reason for withholding sterilisation. A woman in her 20 s or 30 s is legally and socially recognised as an autonomous agent. She is assumed to be sufficiently self-reflective, rational and independent to be able to make significant life-choices and, importantly, free to do so. Doctors do not and should not refuse a patient's request for treatment simply because she is in her 20 s or 30 s.

It seems that two more fundamental concerns lie beneath these worries, which ultimately result in denied requests. Both of them relate to sterilisation's impact upon a woman's future welfare. The first concern is that the woman will regret being sterilised (Campbell 1999; Richie 2013). ${ }^{12}$ Regret is a painful emotion; it can be a source of pain/suffering, as we think of what might have been and reproach ourselves for choosing as we did. The difficulty of reversing sterilisation means women who experience post-sterilisation regret will likely be stuck with it. Such regret may have a significant negative impact upon their well-being. Clinicians could therefore feel justified in preventing women from making choices they will regret. The second concern is that child-free women who are sterilised will be denied the valuable experiences of parenthood which, from gestation onwards, are typically assumed to make a significant contribution to a person's well-being. This can be because the experiences themselves are experientially positive ones and/or because parenthood is intrinsically valuable and an objective component of the good life. A doctor may deny a sterilisation request from a child-free patient because she is foreclosing a key source of her future happiness and fulfillment.

Both concerns demonstrate clinicians' interest in the welfare of their patients. This is certainly laudable. If sterilisation does reduce women's well-being, then clinicians have a principled reason to withhold it. However, for this to be the case, two things need to be established: (1) that sterilisation is sufficiently likely to result in regret and reduced well-being; (2) that concern for patient well-being can override a woman's preference for sterilisation, i.e. the principle of beneficence must be shown to outweigh respect for patient autonomy. I will consider each point in turn.

\section{Post-Sterilisation Regret and Women's Well-Being}

Based on the available data, and contrary to clinicians' worries, post-sterilisation regret is unlikely. In their survey of the data, Curtis et al. (2006, p. 205) conclude that 'most women who undergo sterilisation remain satisfied with their choice of a permanent method of contraception'. Zite and Borrero (2011) report that rates of regret range from 1 to $30 \%$, depending on the research. A study of 3672 women sterilised between 1985 and 1987 found that 7\% experienced an occurrence of regret (Jamieson 2002). In a recent study of 308 Slovenian women, four (1.3\%) of them regretted being sterilised (Becner et al. 2015). Most studies of post-sterilisation

${ }_{12}$ As one consultant said, 'They [women] shouldn't do something they will regret' (quoted in Campbell 1999, p. 122). 
regret do not include information on child-free women, perhaps because most of their requests are denied. One exception is Campbell's (1999) research. Only one of the 23 child-free women interviewed reported post-sterilisation regret. ${ }^{13}$ It is true that studies find younger women are more likely to regret their decision. However, among those under 30 at time of sterilisation, at most $20 \%$ of them report regret 14 years after the procedure (Hillis et al. 1999). If doctors are withholding sterilisation because they think that women are likely to regret their decision, then this belief is not supported by the evidence, even for young and/or child-free women. It should also be noted that women can regret not being sterilised, e.g. in the case of a subsequent unwanted pregnancy. Finally, women can regret aspects of motherhood or having children altogether (Donath 2015) Thus, withholding sterilisation is not guaranteed to prevent regret, whilst allowing access to it for adequately informed, decision-competent women is unlikely to result in regret.

Importantly, being child-free does not seem to result in lower well-being compared with having children. ${ }^{14}$ McLanaham and Adams (1987) examined existing research and concluded that parenthood may have negative consequences for a person's well-being. Simon (2008, p. 41) reports that 'parents in the United States experience depression and emotional distress more often than childless adult counterparts... parents of grown children have no better well-being than adults who never had children'. In a study of 72 females, Jeffries and Konnert (2002) found that those who had chosen to be child-free had higher overall levels of well-being and fewer regrets than mothers. There are, of course, many positive experiences associated with having children, but there seems no support for the claim that having children inevitably makes for a more satisfying, rewarding, enjoyable and/or fulfilling life than one without children. Some women have little or no interest in raising children, or else value greatly activities and projects that are very difficult to reconcile with parenthood. For such women, the claim that their life is devoid of a major source of fulfillment and happiness - that they would be much happier had they become parents-can seem simply false and even insulting. ${ }^{15}$

Finally, women often experience sterilisation as significantly improving their well-being. One way it does this is by eliminating the fear of becoming pregnant. Campbell (1999, p. 158) reports that women who want to live a child-free life often

\footnotetext{
${ }^{13}$ Many participants emphasised their lack of regret and their great relief at being sterilised: 'I have never had any regrets'; 'I remain delighted and totally committed to my decision'; 'I have no regrets, in fact I feel totally relieved and liberated' (Campbell 1999, p. 169).

14 The concept of 'well-being' (which I treat as interchangeable with 'welfare') can be difficult to discuss because there are different accounts of it. In terms of the impact that voluntary sterilisation has on a person's well-being, researchers, and the participants in their studies, may be operating with different understandings of the term. I assume a subjective account of well-being, which is focused on a person's sense of life-satisfaction (see Sumner 1996) but also includes pleasurable/painful experiences. There is not space here to defend this view, although I take it to be plausible.

15 This is especially the case if one opts for a preference account of well-being. An objective account could assert that the woman's life would be better were she a parent, assuming that parenthood is an objective good. Although I cannot make the case here, I take a preference account to be the more plausible of the two. Even if an objective account is right, it would still need to be shown that (biological) parenthood itself is an objective good, rather than loving, fulfilling relationships in general.
} 
'remain deeply, desperately worried about unwanted pregnancy'. For those who do become pregnant, they then face the potentially harrowing decision of whether to have an abortion. Consequently, voluntarily child-free women frequently report 'overwhelming relief' after being sterilised (Campbell 1999, p. 141). ${ }^{16}$ One such woman said she felt 'totally relieved and liberated. It has been a wonderful thing for me' (Campbell 1999, p. 170). Furthermore, 'the feeling of making a commitment to a lifestyle through a permanent procedure [i.e. sterilisation]... can be essential to self-identity, satisfaction, and peace of mind' (Richie 2013, pp. 38-39). Campbell (1999, p. 162) concludes that sterilisation 'is the method which currently offers the highest degree of security and peace of mind to determinedly childfree women'. Consequently, if a woman is confident that she does not want to have any (more) children, then concern for patient well-being does not require that doctors withhold sterilisation from her. Indeed, it seems a strong reason for them to agree to her request.

\section{Respecting Women's Autonomy}

It could be claimed that a reported regret rate of $20 \%$ among younger women is not negligible. Assuming this figure is accurate, it might be high enough to raise serious concerns about offering the procedure to women in their 20s, especially if IUDs can be utilised instead. Furthermore, it is possible that rates of regret for all women increase to a level that people think is troublingly high. If so, this could undermine the case for women's access to sterilisation by providing a strong beneficence argument against it. In response, it is important to emphasise that the possibility of regret applies to many decisions we make, both within and outside of a healthcare context. Despite this, we often permit or even enable people to make these decisions (provided, perhaps, that they are aware they could regret their choice). The reason we do this is because we respect their autonomy. Respect for patient autonomy is a key principle within biomedical ethics (Beauchamp and Childress 2013, pp. 101ff.). It may be unwarranted for a clinician to withhold sterilisation from a decision-competent patient because this undermines or fails to acknowledge her autonomy, which incorporates the ability to make choices that she may later regret. Thus, although discussing the data on post-sterilisation regret and highlighting its rarity is important-not least for women who are considering whether to request sterilisation-this should not displace the greater importance of protecting and enabling autonomous choices, even those that may be regretted.

In order to make this argument, it must be established what it means for a doctor to 'respect' a patient's autonomy, especially when responding to a request for treatment. It is important to note that, as things stand, patients do not have the right to demand specific medical treatment: they are not entitled to it. Respect for patient autonomy does not mean that doctors must obey a patient's wishes. Rather,

\footnotetext{
16 One said that, 'it has been so nice to come off the Pill and not have the fear of pregnancy hanging over me’ (Campbell 1999, pp. 169-170).
} 
it principally means that patients must give their informed consent to the treatments they receive. Patients therefore only have the right to refuse medical treatment. Nevertheless, clinicians do provide some treatments on request, at least when this is made by decision-competent patients. This generates the expectation that such a request will be agreed, so long as the treatment poses no significant risk to the patient's health. Importantly, this applies to forms of contraception such as the pill and IUDs. Arguably, this reflects the generally accepted importance of women's reproductive control, which can be central to their autonomy and well-being. As highlighted above, deciding whether and when to have children is a major part of shaping the life that one wants to lead, especially given the disruptive and negative psychological impact of unwanted pregnancy. It is vital that women are able to control their reproduction. Reflecting this, the UN's Population Fund asserts that women have the right to contraception (UNFPA 2013). ${ }^{17}$ Healthcare should thus enable women's reproductive control by providing their preferred form of contraception. This means that there is - and, importantly, there ought to be-a legitimate expectation that doctors will agree to a decision-competent woman's request for sterilisation, unless there are sufficiently strong countervailing reasons. ${ }^{18} \mathrm{I}$ am suggesting that there are no such reasons. ${ }^{19}$ Thus, with regard to contraception, respect for patient autonomy should mean that patients are able to access their preferred form of it.

This position can be strengthened by arguing that it is not the role of clinicians to shield women from making decisions that they may regret. Respecting someone as autonomous involves allowing them to make such choices, rather than protecting them from all the possible negative consequences of their actions. To quote Richie (2013, p. 39), 'regret is the competent woman's burden, not the doctor's'. Similarly, Brockwell (2015) emphasised her willingness to take responsibility for her choice, which included a refusal to blame doctors if she did later regret being sterilised. We may rightly see it as part of a doctor's ethical duty to make a woman aware of the possibility that she could later change her mind about not having (more) children

\footnotetext{
${ }^{17}$ It has been suggested that there might be a relevant distinction between the negative right not to be made pregnant and the positive right to be sterilised. I am not convinced that this is a useful distinction to draw (beyond the general concern about coherently distinguishing between 'positive' and 'negative' rights). A negative right not to be made pregnant could be reduced to the right that no one impregnates you against your will. However, this seems too limited. People should also be able to engage in nonreproductive sex, which is what effective contraception enables. Thus, the negative right not to be made pregnant should incorporate the right to engage in non-reproductive sex, or else people should also possess the positive right to effective contraception. Either way, clinicians have a positive obligation to provide birth control. The issue is whether sterilisation should be one of the forms of contraception that doctors are required to offer to patients. I am arguing that it is.

18 Such an expectation can partly explain the distress women express in having their requests denied. After having her request summarily dismissed by a consultant, one child-free woman wrote, 'I couldn't believe that I was being ignored in such a way, this was my LIFE he was dismissing... Afterwards, I found that I was shaking with anger and cried quite a lot in the toilets' (Campbell 1999, p. 114).

19 One caveat to this is that clinicians can refuse to perform some requested procedures on conscientious grounds, which has occurred with regard to both abortion and sterilisation. Assuming a conscience clause should be attached to sterilisation, the doctor in question would be required to refer the patient to clinicians who will perform the procedure.
} 
and regret being sterilised. However, it is unwarranted for doctors to withhold sterilisation from a decision-competent woman who accepts the risk of regret and still desires to undergo the treatment. Additionally, it can be problematic if doctors tell a patient that she will regret her decision when, following careful self-reflection, she is confident that she will not. This presumes an epistemic authority over the woman regarding her feelings and preferences.

It thus seems objectionably paternalistic for clinicians (a) to protect a patient from making a choice she might regret, especially when she is confident she will not do so or is untroubled by this possible outcome; and/or (b) suggest that they know what is best for the woman-e.g. that she leaves the option of having (more) children open or that having a child will be good for her-when she is certain that she wants to commit to a child-free life or to maintain her current family size. These issues are evident in the experiences of child-free women requesting sterilisation, who said they were often made to feel like infants by their doctors (Campbell 1999, p. 123). A 31-year-old woman said that her consultant "came out with the statement that I was only a kid and that I didn't know what I was missing by not having children... she said I would soon be back to have the operation reversed' (Campbell 1999, p. 125-126). Another said, 'When I finally saw a consultant he laughed at my request and told me to come back when I was married and had had kids' (Campbell 1999, p. 114). The clinicians' behaviour represents a serious failure to respect their patient's status as self-reflective, autonomous agents and the authority this grants them over their contraceptive choices. Part of respecting a patient's autonomy involves respecting their preferences and desires, even when they differ significantly from the doctor's own or from what the doctor thinks the patient's preferences and desires should be. It also involves permitting decision-competent patients to make decisions that they may regret. Doctors ought not override a patient's autonomy, or conclude that the patient is non-competent, just because they themselves would not make this choice or do not share the patient's views about reproduction, motherhood and/or whether possible regret should be avoided. ${ }^{20}$

A final issue to consider is how to balance the principles of beneficence and respect for patient autonomy. Is one more important/weightier than the other? Several points suggest that, with regard to voluntary sterilisation, doctors should place greater emphasis on patient autonomy when responding to a request. First, it is very difficult, if not impossible, to ascertain what an individual's future well-being will be like, including whether they will regret their decision. It is affected by a myriad of factors and determined by events that can neither be foreseen nor fully controlled. This makes it difficult to know now which decisions will best promote their wellbeing in the long term. ${ }^{21}$ What can be known with relative certainty is whether the woman is competent to make a decision about her method of contraception. Thus, we can respect her autonomy even if we cannot know how she will feel many years

\footnotetext{
${ }^{20}$ My thanks to an anonymous reviewer for making this point.

21 At least with regard to some choices, such as what method of contraception to use, whether to have a child, what career to pursue, which person to marry, etc. One can be sufficiently certain that infecting a person with a fatal disease against their wishes will not be good for them.
} 
later about her decision and what its impact upon her well-being will be. Second, medical paternalism is generally frowned upon and refusing a patient's request for sterilisation on the basis that the doctor knows what is best for her future well-being can seem to be objectionably paternalistic. Third, refused sterilisation requests can be experienced as distressing and/or disrespectful, which will impact negatively upon well-being. Thus, respecting patient autonomy will often help to serve the goal of promoting patient well-being. These observations also reinforce the claim that the defence of voluntary sterilisation should rest more on women's autonomy and reproductive control than on levels of post-sterilisation regret.

\section{The Impact of Pronatalism on Women's Sterilisation Requests}

I have argued that some women have good reason to request sterilisation, even when they can utilise other forms of contraception, and that these requests should be agreed to by doctors when made by decision-competent adults. In addition to constructing this philosophical defence of voluntary sterilisation, it is important to consider contraceptive decision-making in everyday, non-ideal contexts. Here, a woman's identity can shape her own contraceptive decision-making as well as how her choice is understood and responded to by doctors. My focus is primarily on how women's identity is perceived by doctors. The reason for this is that doctors ultimately decide whether to agree to a sterilisation request and hence control access to it. $^{22}$ Thus, how doctors recognise women, and how this affects their recognition of women's autonomy and epistemic authority, is of great importance.

One factor that appears to shape clinicians' responses to a woman's sterilisation request is her gender. It seems to be significantly easier for men to obtain sterilisation than women (Richie 2013). ${ }^{23}$ This could be because 'men are less bound by cultural norms of parenthood and [assumed to be] more competent to make decisions' (Richie 2013, p. 40). Furthermore, implicit gender bias in healthcare appears to be well-documented (Hamberg 2008). For example, men are three times more likely than women to receive knee arthroplasty when clinically appropriate (Chapman et al. 2013, p. 1507). One explanation for this is that men are presumed to be more stoic and hence better able to cope with treatment (Chapman et al. 2013, p. 1507). Given that doctors often worry about post-sterilisation regret, they could be more willing to sterilise men because they assume that they will cope better with any regrets that arise. Similarly, men may be assumed to know their own mind better than women, and hence more capable of knowing for certain what their core

\footnotetext{
22 I cannot address here whether this relationship should be altered or, indeed, eradicated. For example, condoms are 'de-medicalised' in the sense that access to them is not controlled by clinicians. One can imagine the development of a home sterilisation kit, which could be purchased from licensed shops by anyone over a certain age. This would remove the problem of women being denied access to sterilisation by doctors, although there could still be compelling arguments against it.

23 Although this observation must be accompanied by the caveats that (a) there is very little information available on male sterilisation requests and their acceptance rates; and (b) male vasectomy is more easily reversed than female sterilisation.
} 
preferences are and whether they might change their mind later. Finally, it is possible that men are more assertive and perceived to be more confident, which makes it easier for them to obtain their desired treatment, especially when their doctors have doubts about providing it. ${ }^{24}$

It is also important to consider VS in relation to the prominence of pronatalism within society. Pronatalism can be defined as 'an attitudinal stance that favours and encourages childbearing... [and] supports policies and practices that construe and venerate motherhood as the sine qua non of womanhood' (Gotlib 2016, p. 331). ${ }^{25}$ It is thus founded upon, and reinforces, the equation of woman with motherhood (Morrell 1994; Gillespie 2003; Kelly 2009). Furthermore, it asserts that motherhood is a/the primary source of a woman's happiness and fulfilment, a message that is oft-repeated in literature, film, advertising, medical practice and government policy (Gotlib 2016). This results in an entrenched assumption/expectation that women will and should want to reproduce. A further effect of pronatalism is that women who voluntarily forego motherhood are often portrayed as, and assumed to be deviant, incomplete, miserable, bitter, unfulfilled, unnatural and/or selfish (Campbell 1999; Gillespie 2000; Park 2002; Gotlib 2016). Being child-free is thus described as a stigmatised identity (Veevers 1980; Park 2002). From a pronatalist perspective, women who seek sterilisation go against their perceived nature qua woman. Morrell (1994, p. 77) observes that many people assume that 'only women who are morally suspect or flawed by events beyond their control would reject motherhood'. Similarly, as Gillespie (2000, p. 225) argues, 'Failure to become a mother is interpreted within a western biomedical framework as a physical or psychological illness'.

In light of this, doctors may treat child-free women's sterilisation requests with suspicion or dismiss them altogether, as it is assumed that no rational and self-reflective woman would willingly forego having children of her own. ${ }^{26}$ The reason given for their denied requests is 'often related to the medic's fundamental belief that no mature woman could reach such a decision [to be sterilised] and that she will eventually grow out of her infant state, will reach maturity and will then wish to have children' (Campbell 1999, p. 115). This suggests that child-free women face a credibility deficit in having to prove the validity and acceptability of their feelings and decision to be child-free and/or sterilised (Gillespie 2000; Park 2002; Gotlib 2016).

\footnotetext{
24 The recognition of women's autonomy and decision-making capacity will itself be affected by their particular identity, including their socio-economic status, ethnicity and race. For example, women who are poor and/or without educational qualifications may be viewed as less autonomous than other women.

25 It should be noted that not all women's child-bearing is equally valued. For example, poor and/ or minority women may be discouraged from reproducing, and some countries have forcibly sterilised them (Kluchin 2009). This may make it easier for them to access sterilisation. However, black women are also associated strongly with motherhood in certain cultural representations of them (e.g. the AfricanAmerican 'mamma'), which may make it more likely that their request is denied. Wealthy, white and/or educated women may find it harder to have their sterilisation request agreed to, because they are seen as ideal mothers. Overall, there is a confluence of factors that affect how women's requests are responded to, which may push in different directions.

${ }^{26}$ Following another denied request for sterilisation, one child-free women wrote that 'Yet again a member of the medical profession dismissed my concerns and beliefs without even listening to what I had to say’ (Campbell 1999, p. xxii).
} 
Women with one or two children also experience this difficulty, as it will be assumed that they will want to have more children in the future. Such scepticism also reveals a questionable asymmetry between how requests for medical assistance in reproduction, e.g. for IVF, are responded to and how sterilisation requests are responded to. Women who seek sterilisation are required to go through a much more extensive process of justification than women who want to become pregnant, even though both are significant, permanent life-choices. Indeed, choosing to have a child constitutes a major life-changing event, whereas deciding not to have a child involves maintaining one's life as it is. This could mean that requests for IVF should be treated as much more significant and hence subjected to greater scrutiny by clinicians.

The effects of pronatalism are also relevant to understanding post-sterilisation regret and clinicians' worries about it. People, including doctors, may expect a childfree woman to regret being sterilised and be suspicious of her if she does not. This expectation could foreclose doctors' ability to imagine a child-free woman living a fulfilling life. It also reveals a failure to consider other ways that women can become mothers, including adoption and marrying into a family, or the assumption that these are less fulfilling and/or valuable routes to motherhood. Furthermore, it is possible that some sterilised women's regret is induced or deepened by the clear, persistent message that a woman's happiness consists in having children. As a result of people's responses to her decision, including the expectation that she will come to regret it, and the wider societal depiction of female identity in terms of motherhood, she herself may come to feel that she has made a poor decision and that her life would have been better if she had had children of her own. If being child-free were less stigmatised, and pronatalism less pervasive, then there might be fewer occurrences of post-sterilisation regret and less expectation and/or worry that it will arise.

It is important to note that doctors who are reluctant to agree to sterilisation requests may not endorse pronatalism. They may think that women will inevitably bow to pronatalist pressures, without thinking that this is a good thing. Thus, they may be acting in what they take to be women's best interests, given their assumption about what her future preferences will be. Nevertheless, they would still be (a) making the problematic assumption that women are likely to change their mind about not having any (more) children and hence to regret their decision; and (b) failing to respect women's autonomy by overriding their expressed preferences and preventing them from making a decision they may regret. One way of alleviating concerns about, and occurrences of, post-sterilisation regret is to challenge pronatalist discourses that portray a child-free life as necessarily less fulfilling than parenthood. An important part of this consists in promoting counter-narratives of happily childfree women and/or sterilised women who are regret-free. This will help women deliberating about what form of contraception to use, as they may feel more confident/accepting of their own desire for a child-free life. It will also reassure doctors who are worried about the adverse effect of sterilisation on women's future wellbeing, hopefully making it more likely that they will agree to sterilisation requests from decision-competent women. 


\section{Conclusion}

Women's bodily autonomy and the importance of reproductive freedom/control provide a strong argument in favour of women's access to sterilisation. To bolster this claim, I have shown why some women can prefer sterilisation to other forms of contraception, even if they are young and/or child-free. Denied sterilisation requests thus require a good justification. I have argued that the main reasons offered by doctors for withholding access to it-that the woman is too young, child-free and/or likely to regret her decision-are unconvincing at both an empirical and a normative level. Consequently, decision-competent women should have their sterilisation requests agreed to. I have also shown that pronatalism can shape how requests for sterilisation are responded to by doctors. The equation of women with motherhood, and the assumption that motherhood is central to a woman's happiness and fulfillment, can make it unustifiably hard for women to access sterilisation, especially if they are child-free. Pronatalism may also generate the unfounded concerns held by some doctors that women are likely to regret being sterilised and that it will lower their well-being. Contrary to these worries, a child-free life can be a happy and fulfilling one, and decision-competent women rarely regret being sterilised. Furthermore, even if doctors do hold such worries, then respect for patient autonomy and the importance of women enjoying reproductive control entail that their sterilisation requests should be agreed to.

Acknowledgements My sincere thanks to Cillian McBride and two anonymous referees for their comments on versions of this article.

Open Access This article is distributed under the terms of the Creative Commons Attribution 4.0 International License (http://creativecommons.org/licenses/by/4.0/), which permits unrestricted use, distribution, and reproduction in any medium, provided you give appropriate credit to the original author(s) and the source, provide a link to the Creative Commons license, and indicate if changes were made.

\section{References}

Beauchamp, Tom L., and James F. Childress. 2013. Principles of biomedical ethics. Oxford: Oxford University Press.

Becner, Anja, Anela B. Turkanović, and Igor But. 2015. Regret following female sterilization in Slovenia. International Journal of Gynecology \& Obstetrics 130(1): 45-48.

Benn, Piers, and Martin Lupton. 2005. Sterilisation of young, competent, and childless adults. British Medical Journal 330(7503): 1323-1325.

Borrero, Sonya, et al. 2008. 'Everything I know I learned from my mother...or not': Perspectives of African-American and white women on decisions about tubal sterilization. Journal of General Internal Medicine 24(3): 312-319.

Brockwell, Holly. 2015. Why can't I get sterilised in my 20s? The Guardian. https://www.theguardia n.com/commentisfree/2015/jan/28/why-wont-nhs-let-me-be-sterilised. Accessed 4 September 2019.

Buchanan, Allen, and Dan Brock. 1989. Deciding for others: The ethics of surrogate decision making. Cambridge: Cambridge University Press.

Campbell, Annily. 1999. Childfree and sterilized: Women's decisions and medical responses. London: Cassell.

Chapman, Elizabeth D., Anna Kaatz, and Molly Carnes. 2013. Physicians and implicit bias: How doctors may unwittingly perpetuate health care disparities. Journal of General Internal Medicine 28(11): 1504-1510. 
Curtis, Kathryn M., Anshu P. Mohllajee, and Herbert B. Peterson. 2006. Regret following female sterilization at a young age: A systematic review. Contraception 73(2): 205-210.

Donath, Orna. 2015. Regretting motherhood: A sociopolitical analysis. Signs 40(2): 343-367.

Dworkin, Gerald. 1982. Is more choice better than less? Midwest Studies in Philosophy 7(1): 47-61.

Ganzini, Linda, Volicer Ladislav, William A. Nelson, and Ellen Fox. 2004. Ten myths about decisionmaking capacity. Journal of the American Medical Directors Association. 5: 263-267.

Gillespie, Rosemary. 2000. When no means no: Disbelief, disregard and deviance as discourses of voluntary childlessness. Women's Studies International Forum 23(2): 223-234.

Gillespie, Rosemary. 2003. Childfree and feminine: Understanding the gender identity of voluntarily childless women. Gender and Society 17(1): 122-136.

Gotlib, Anna. 2016. 'But you would be the best mother': Unwomen, counterstories, and the motherhood mandate. Journal of Bioethical Inquiry 13(2): 327-347.

Hamberg, Katarina. 2008. Gender bias in medicine. Women's Health 4(3): 237-243.

Higgins, Jenny, and Jennifer S. Hirsch. 2008. Pleasure, power, and inequality: Incorporating sexuality into research on contraceptive use. American Journal of Public Health 98(10): 1803-1812.

Hillis, Susan D., Polly A. Marchbanks, Lisa R. Tylor, and Herbert D. Peterson. 1999. Poststerilization regret: Findings from the United States collaborative review of sterilization. Obstetrics \& Gynecology, 93(6): 889-895.

Jackson, Emily. 2001. Regulating reproduction: Law, technology and autonomy. Oxford: Hart Publishing.

Jamieson, Denise. 2002. A comparison of women's regret after vasectomy versus tubal sterilization. Obstetrics and Gynecology 99(6): 1073-1079.

Jeffries, Sherryl, and Candace Konnert. 2002. Regret and psychological well-being among voluntarily and involuntarily childless women and mothers. The International Journal of Aging and Human Development 54(2): 89-106.

Kelly, Maura. 2009. Women's voluntary childlessness: A radical rejection of motherhood? Women's Studies Quarterly 37(3/4): 157-172.

Kluchin, Rebecca M. 2009. Fit to be tied: Sterilization and reproductive rights in America, 1950-1980. New Brunswick, NJ: Rutgers University Press.

Lawrence, R. E., K. A. Rasinski, J. D. Yoon, and F. A. Curlin. 2011. Factors influencing physicians' advice about female sterilization in USA: A national survey. Human Reproduction (Oxford, England) 26(1): 106-111.

McLanaham, Sarah, and Julia Adams. 1987. Parenthood and psychological well-being. Annual Review of Sociology 13: 237-257.

Morrell, Carolyn M. 1994. Unwomanly conduct: The challenges of intentional childlessness. New York, NY: Routledge.

National Health Service. 2015. Female sterilisation. National Health Service Choices. http://www.nhs. uk/Conditions/contraception-guide/Pages/female-sterilisation.aspx. Accessed 15 Aug 2019.

Park, Kristin. 2002. Stigma management among the voluntarily childless. Sociological Perspectives 45(1): 21-45.

Park, Kristin. 2005. Choosing childlessness: Weber's typology of action and motives of the voluntarily childless. Sociological Inquiry 75(3): 372-402.

Richie, Cristina. 2013. Voluntary sterilization for childfree women: Understanding patient profiles, evaluating accessibility, examining legislation. The Hasting Center Report 43(6): 36-44.

Simon, Robin W. 2008. The joys of parenthood, reconsidered. Contexts 7(2): 40-45.

Sumner, Leonard W. 1996. Welfare, happiness and ethics. Oxford: Oxford University Press.

Trussell, James, Anjana Lalla, Quan Doan, Eileen Reyes, Lionel Pinto, and Joseph Gricar. 2009. Cost effectiveness of contraceptives in the United States. Contraception 79(1): 5-14.

UNFPA. 2013. Choices not chance. United Nations Population Fund. https://www.unfpa.org/publicatio ns/choices-not-chance. Accessed 15 Aug 2019.

Veevers, Jean E. 1980. Childless by choice. Toronto: Butterworths.

Zite, Nikki, and Sonya Borrero. 2011. Female sterilisation in the United States. The European Journal of Contraceptive and Reproductive Health Care 15(5): 336-340.

Publisher's Note Springer Nature remains neutral with regard to jurisdictional claims in published maps and institutional affiliations. 